\title{
Efecto de la inclusión de ensilado químico de vísceras de tilapia roja (Oreochromis spp.) en dietas para pollos de engorde sobre los parámetros productivos y sanguíneos
}

\author{
Yhoan S. Gaviria ${ }^{1}$, Omar A. Figueroa ${ }^{2}$ y José E. Zapata ${ }^{1 \star}$ \\ (1) Grupo de Investigación en nutrición y tecnología de alimentos, NUTEC, Universidad de Antioquia, Medellín, Colombia \\ (correo-e: yhoan.gaviria@udea.edu.co; edgar.zapata@udea.edu.co) \\ (2) Facultad de Ingeniería, Universidad de la Guajira, Riohacha, Colombia (correo-e: omfimo22@gmail.com)
}

*Autor a quien dirigir la correspondencia.

Recibido Oct. 26, 2020; Aceptado Dic. 28, 2020; Versión final Ene. 30, 2021, Publicado Jun. 2021

\begin{abstract}
Resumen
En el presente estudio se analizó el efecto sobre las variables productivas y parámetros sanguíneos de la inclusión de ensilado químico de vísceras de tilapia roja (Oreochromis spp.) como fuente de proteína principal en dietas para pollos de engorde de la línea Ross 308. Para esto, se evaluaron las variables productivas de peso semanal, talla, consumo de alimento, conversión de alimento y mortalidad, así como los parámetros sanguinos y el hemograma. Las variables productivas del alimento experimental presentaron diferencias estadísticamente significativas respecto al control en el parámetro de peso semanal (1684 y $1830 \mathrm{~g}$ respectivamente), mientras los componentes sanguíneos de ambas dietas estuvieron en el rango normal. En conclusión, el ensilado químico de vísceras de tilapia roja cuenta con las características bromatológicas y microbiológicas para ser usado en la alimentación de pollos de engorde, sin presentar efectos adversos sobre sus variables productivas ni parámetros sanguíneos.
\end{abstract}

Palabras clave: ensilado químico; Ross 308; hemograma; vísceras de tilapia; alimento para pollos

\section{Effect of the inclusion of red tilapia (Oreochromis spp.) chemical viscera silage in broiler feed and its effect on productivity and blood parameters}

\begin{abstract}
The primary objective of the present study is to assess the effect on broiler (Ross 308 line) productivity and broiler's blood after adding red tilapia (Oreochromis spp.) chemical viscera silage to the feed as a main protein source. The productivity variables examined were weight gain, height, feed consumption, feed conversion, and mortality. Blood parameters were measured, including hemograms. The results show that the productivity variables differed significantly in the weekly weight parameter between the experimental food and the control (1684 and $1830 \mathrm{~g}$ respectively). However, the blood variables in both the experimental and control diets were found to be within normal ranges. In conclusion, the chemical silage of red tilapia viscera meets the bromatological and microbiological characteristics required for feeding broilers, without causing adverse effects on productivity or blood parameters.
\end{abstract}




\section{INTRODUCCIÓN}

La avicultura industrial es una cadena eficiente de obtención de proteína animal de alta calidad y bajo costo, por lo que la carne de pollo comprende un alimento completo, sano y accesible para millones de personas alrededor del mundo (Nunes, 2009). Sin embargo, del costo total de la alimentación la mayor parte es destinado a satisfacer las necesidades de proteína y energía, siendo la harina de pescado y la torta de soya las principales fuentes de proteína animal y vegetal, respectivamente (Leinonen et al., 2012). Sin embargo, estas materias primas no siempre están disponibles en las cantidades requeridas en todos los países, como es el caso de Colombia, país que debe abastecerse de importaciones provenientes de grandes productores como Estados Unidos y Brasil. Es por esto, que se vuelve indispensable encontrar alternativas de alimentación en la industria avícola que ayuden a bajar los costos de producción, sin influir negativamente en la eficiencia y sostenibilidad de los sistemas.

En este sentido los residuos de la industria piscícola ricos en proteína, como es el caso de las vísceras, surgen como alternativa para la preparación de insumos que puedan ser utilizados en la industria de alimentación animal, puesto que este tipo de residuos ha experimentado un marcado incremento asociado al aumento en la producción piscícola en las últimas décadas llegando en 2016 a 171 millones ton a nivel global (Suarez et al., 2018). Por su parte, Colombia con una tendencia similar, llegó en 2017 a 120.230 ton, en las que el 62\% correspondió a tilapia roja (Suarez et al., 2018). Al respecto, el proceso de ensilaje de vísceras de pescado se ha implementado con éxito aportándole valor agregado, extendiendo el periodo de conservación y mejorando su composición nutricional (Gaviria et al, 2020).

El ensilaje de pescado es un proceso que se basa en el descenso del pH para activar las enzimas endógenas e inhibir la flora patógena. Para esto se adicionan agentes acidificantes como ácidos, enzimas o bacterias acido-lácticas, con lo que se promueve la licuefacción de la masa por la acción hidrolítica de sobre las proteínas (Fernández Herrero et al. 2013). Por lo que el producto obtenido, contiene proteínas parcialmente hidrolizadas, con propiedades nutricionales muy similares a las del pescado de origen, es semilíquido pastoso, color pardo grisáceo, olor característico a pescado, el cual puede ser almacenado durante varios meses sin requerir refrigeración (Gaviria et al., 2020). Ensilados de subproductos de pescado, se han empleado con éxito en el diseño de alternativas de nutrición para aves, incluyendo pollos de engorde (Gómez et al., 2014). Sin embargo, resulta de gran importancia científica complementar el análisis de los parámetros de nutricionales y zootécnicos, con los indicadores confiables del estado de salud y expresión fisiológica de los pollos. El objetivo del presente trabajo fue evaluar el efecto de la inclusión de ensilado químico de vísceras de tilapia roja (Oreochromis spp.) en dietas para pollos de engorde de la línea Ross 308, sobre las variables productivas y los parámetros sanguíneos de las aves.

\section{METODOLOGÍA}

La metodología presenta varias subsecciones, inicialmente se describió la preparación del ensilado químico (EQ), seguido por la caracterización bromatológica y microbiológica del mismo, la alimentación de las aves, la evaluación de las variables productivas, la cuantificación de la química sanguínea y el hemograma, por último, se estableció el análisis estadístico.

\section{Obtención de ensilado químico}

Las vísceras de tilapia roja (Oreochromis spp.) fueron obtenidas de la piscícola El Gaitero, ubicada en San Jerónimo, Antioquia-Colombia. Luego del proceso de eviscerado, las vísceras se trasladaron al laboratorio, donde fueron desengrasadas mediante calentamiento a $67^{\circ} \mathrm{C}$ por 30 minutos, dejando descender la temperatura hasta $45^{\circ} \mathrm{C}$, para luego llevar a congelación $\left(-18^{\circ} \mathrm{C}\right)$ por $24 \mathrm{~h}$. Este proceso mejora la separación del aceite y la fase acuosa congelada, la cual es rica en proteínas (Arias et al., 2017). Antes de su uso, la fase acuosa fue triturada por medio de un molino de cuchillas para su homogeneización, posteriormente se mezcló con $0,03 \%$ de ácido sulfúrico al $97 \%$ (Merck, Alemania) y 1,16\% ácido fórmico al 85\% (Merck, Alemania) para dar inicio al proceso de hidrólisis y acidificación, después se adicionó BHT (Butil hidroxi tolueno) (Tecnas S.A, Colombia) y sorbato de potasio (Tecnas S.A, Colombia) como antioxidante y conservante, respectivamente. Finalmente, la mezcla se almacenó a $25^{\circ} \mathrm{C}$ durante 8 días, tiempo durante el cual se homogenizó el producto mediante agitación y se hizo controles de $\mathrm{pH}$ cada 2 días, hasta que alcanzara un valor de 4 en el que se estabilizaba.

\section{Composición bromatológica y microbiológica}

La caracterización fisicoquímica de las vísceras frescas y el ensilado químico, se realizó de acuerdo con lo establecido por la Association of Official Analytical Chemists (AOAC). El contenido de humedad se determinó mediante de la norma 930.15 , secando la muestra a $105^{\circ} \mathrm{C}$ en una estufa convectiva (Thermo Scientific ${ }^{\mathrm{TM}}$, 
USA), durante 8 horas. La proteína fue determinada por el método Kjeldahl, norma 954.01. Las cenizas se analizaron con la norma 942.05, en una mufla (Terrigeno, Colombia). El análisis de grasas según la metodología 920.39 implementando un sistema soxhlet (Radlys, USA), por último, los carbohidratos se determinaron sustrayendo al cien por ciento de la muestra los demás componentes mencionados (Spanopoulos-Hernandez et al. 2010). Los análisis microbiológicos se determinaron mediante la Norma Técnica Colombiana NTC 3688, en la que se establece para este tipo de sustrato el análisis de mesófilos aerobios, coliformes totales y fecales, Salmonella spp, espora Clostridium sulfito reductor y mohos y levaduras.

\section{Alimentación de aves}

Pollos de engorde (Gallus gallus domesticus) de la línea genética Ross 308 de 1 día de nacidos, fueron distribuidos aleatoriamente en dos grupos iguales denominados control (CD) y ensilado (ED), los cuales a su vez se dividieron en 6 repeticiones, de 5 aves cada uno, para un total de 60 aves, las cuales se alimentaron durante 40 días. El grupo CD recibió una dieta cuya proteína provenía de materias primas convencionales como la harina de pescado y la torta de soya, mientras que grupo de prueba ED se alimentó con una dieta que contenía $25,5 \%$ de ensilado de vísceras de tilapia roja (Oreochromis spp.). Las aves fueron alimentadas dos veces al día con una ración por ave, que aumentaba semanalmente (valores de alimento), además de tener el suministro de agua constante ad libitum.

\section{Variables productivas}

Las variables productivas fueron registradas semanalmente. Se evaluó el peso semanal de las aves mediante el uso de una balanza analítica con precisión de un 1g, TxB220-1L (Shimadzu, Japan), la talla de las aves se determinó mediante un vernier, midiendo el hueso tarso-metatarso, el índice de conversión de alimento se calculó como la relación entre el alimento consumido y la ganancia de peso de cada ave y por último se determinó el porcentaje de mortalidad en ambas dietas.

\section{Química sanguínea y hemograma}

El hemograma fue determinado usando la metodología propuesta por Clark et al., (2012), que cuenta con hematocritos, hemoglobina, glóbulos blancos o leucocitos, además de heterófilos $(H)$, linfocitos $(L)$ eosinófilos (E), monocitos (M) y basófilos (B). Con respecto a la química sanguínea se determinaron los niveles plasmáticos de la enzima alanina aminotransferasa (ALT), las proteínas totales (PT), colesterol (CT) y triglicéridos (TG) mediante lo establecido por Franco-G et al., (2009). Las muestras de sangre fueron tomadas de la vena del ala a tres aves de cada grupo, con 40 días de edad, con o sin anticoagulantes de acuerdo con los requerimientos de la prueba. Se analizaron muestras de plasma para determinar las concentraciones de colesterol total, proteína total, triglicéridos, fosfatasa alcalina y la enzima alanina aminotransferasa (ALT).

\section{Análisis estadístico}

Los datos recopilados fueron evaluados mediante la prueba de hipótesis para determinar diferencia de medias entre las variables productivas usando la prueba LSD (Least significant difference) de Fischer mediante el software Statgraphics Centurion XVI, con un nivel de confianza del 95\%, verificando la normalidad independencia y homogeneidad de los datos.

\section{RESULTADOS Y DISCUSIÓN}

En la tabla 1 se presenta la composición bromatológica de las vísceras de tilapia Roja (Oreochromis spp.) y el ensilado químico, después del periodo de almacenamiento. La caracterización proximal de las vísceras frescas es similar a la reportada por Arias et al., (2017) para la misma especie. Por otra parte, se nota un aumento de aproximadamente $50 \%$ en el valor de la proteína del ensilado con respecto a las vísceras frescas, debido principalmente al proceso de desengrasado, que reduce la grasa aproximadamente en un $80 \%$, esta misma tendencia fue observada por Spanopoulos-Hernandez et al.,(2010) en la producción de ensilado biológico de filete de tilapia.

Con referencia al ensilado, se obtuvieron las propiedades típicas con consistencia semilíquida pastosa, color pardo grisáceo, olor característico a pescado (Botello, 2010). Debido a su composición nutricional este es un insumo ideal para alimentación animal (Botello, 2010; Suarez et al., 2018; Gaviria et al., 2020). Los macro compuestos como proteínas y lípidos del ensilado de residuos de tilapia, se han usado para alimentación de diferentes especies herbívoras y omnívoras principalmente, con resultados satisfactorios, siendo utilizado como sustituto parcial de la harina de pescado la cual es considerada la fuente de proteína de origen animal más utilizada en alimentación para los mismos, justamente por su digestibilidad y contenido proteico (Gaviria 
et al., 2020). De esta manera esta investigación se enmarca en la tendencia actual de evaluar los efectos de usar mezclas de fuentes piscícolas con el fin de reducir el impacto ambiental que genera la piscicultura (Suarez et al., 2018).

Tabla 1. Composición bromatológica de vísceras y ensilado químico de tilapia roja.

\begin{tabular}{|l|c|c|}
\hline \multicolumn{1}{|c|}{ Componente } & Vísceras frescas & Ensilado químico \\
\hline Humedad (\%) & $61.36 \pm 0.29$ & $80.27 \pm 0.09$ \\
\hline Proteína (\%) & $4.03 \pm 0.10$ & $8.85 \pm 0.04$ \\
\hline Grasa (\%) & $32.93 \pm 0.04$ & $7.08 \pm 0.01$ \\
\hline Cenizas (\%) & $0.67 \pm 0.04$ & $2.69 \pm 0.01$ \\
\hline Carbohidratos (\%) & $0.98 \pm 0.09$ & $0.11 \pm 0.02$ \\
\hline
\end{tabular}

Por otra parte la composición microbiológica del ensilado (tabla 3) se encuentra dentro de los parámetros establecidos en la norma nacional colombiana para insumos de alimentación animal, destacándose la ausencia de baterías patógenas como Coliformes fecales, Salmonella spp y esporas de Clostridium, las cuales son inhibidos por la acidificación del ensilaje, con lo cual puede ser usado como materia prima en la elaboración de dietas para alimentación animal sin causar efecto observó a causa de estos microorganismos (Spanopoulos-Hernandez et al. 2010).

Tabla 2. Composición microbiológica de ensilado químico.

\begin{tabular}{|l|l|l|}
\hline Análisis & Valor & Requisitos \\
\hline Mesófilos aerobios (ufc/ml) & $5 \times 10^{2}$ & $10 \times 10^{5}$ \\
\hline Coliformes totales (ufc/ml) & $3.5 \times 10^{1}$ & $10 \times 10^{4}$ \\
\hline Coliformes fecales & Ausencia & Ausencia \\
\hline Salmonella Spp. & Ausencia & Ausencia \\
\hline Espora clostridium sulfito & Ausencia & $20 \times 10^{1}$ \\
\hline Mohos y levaduras (ufc/ml) & $8.2 \times 10^{1}$ & $10 \times 10^{4}$ \\
\hline
\end{tabular}

En función de la composición fisicoquímica del ensilado obtenido se desarrolló una dieta experimental, la cual tenía una sustitución parcial de las materias primas proteicas por ensilado, logrando una sustitución del $25.5 \%$ en base seca del total de la formulación. Adicionalmente se realizó una dieta control utilizando las materias primas proteicas convencionales (torta de soya y harina de pescado) sin sustitución de ensilado químico. Para el balance de nutrientes de ambas se dietas se implementaron las tablas brasileñas para alimentación de aves, logrando un balance adecuado de los nutrientes para la especie seleccionada (tabla 3).

Tabla 3. Dietas experimentales y composición.

\begin{tabular}{|l|c|c|}
\hline Materias primas & Dieta control (\%) & Dieta ensilado (\%) \\
\hline Harina de maíz & 33 & 40 \\
\hline Harina de arroz & 26 & 17 \\
\hline Ensilado & 0 & 25.5 \\
\hline Torta de soya & 18 & 9 \\
\hline Harina de pescado & 16 & 5 \\
\hline Aceite de pescado & 3.5 & 0 \\
\hline Carbonato de calcio & 1 & 1 \\
\hline Fosfato de cálcico & 1 & 1 \\
\hline Suplemento Vitaminas & 0.50 & 0.50 \\
\hline Lisina & 0.25 & 0.25 \\
\hline Metionina & 0.25 & 0.25 \\
\hline Triptófano & 0.25 & 0.25 \\
\hline Treonina & 0.25 & 0.25 \\
\hline Composición química & \multicolumn{2}{|l|}{} \\
\hline Proteína (\%) & 20.50 & 21.10 \\
\hline Carbohidratos (\%) & 41.05 & 41.00 \\
\hline Grasa cruda (\%) & 9 & 7.4 \\
\hline $\begin{array}{l}\text { Energía metabolizable } \\
\text { (Kcal/kg) }\end{array}$ & 3676 & 3500 \\
\hline Calcio (\%) & 1.3 & 1.10 \\
\hline Fósforo (\%) & 0.70 & 0.60 \\
\hline \multicolumn{2}{|c|}{} & \\
\hline & & \\
\hline
\end{tabular}


Adicionalmente se utilizó una premezcla de vitaminas y minerales la cual presenta la siguiente composición por 250 g de producto: vit. A - 1,400,000 IU; vit. B1 - $500 \mathrm{mg}$; vit. B12 - $300 \mathrm{mg}$; vit. B2 = 500 mg; vit. B6 - 1,6 g; vit. D3 - 2,500,000 IU; vit. E - 6,000 IU; vit. K3 = 1,000 mg; biotina - $30 \mathrm{mg}$; niacina -12 g; ácido fólico - $1 \mathrm{~g}$; cobalto - $50 \mathrm{mg}$; cobre - 3,000 mg; hierro - $25 \mathrm{~g}$; yodo - $500 \mathrm{mg}$; manganeso - $32.5 \mathrm{~g}$; selenio - $100.50 \mathrm{mg}$; zinc - $22.49 \mathrm{~g}$.

En la figura 1 se presentan los valores de las variables productivas de peso durante las semanas de estudio y talla de las aves, en función del tiempo. En ella se observa como para la ganancia de peso los resultados de ambas dietas (CD y ED) presentan una tendencia similar, sin diferencias estadísticamente significativas ( $P$ $<0,05)$ entre la semana 0-5, sin embargo, en la semana 6 se observa que el peso de las aves alimentadas con la dieta ED es estadísticamente menor que el de las alimentadas con CD. No obstante, los pesos obtenidos para esta dieta se encuentran en el rango típico para esta línea de aves (Ross 308) (Rosero et al., 2012). Es así como Boitai et al., (2018) y Venturoso et al., (2016) obtuvieron pesos de 1701 y $1660 \mathrm{gr}$, respectivamente, en pollos de engorde alimentados a partir de dietas con sustitución parcial de la proteína por ensilado químico de vísceras y branquias de peces de agua dulce, concluyendo que la sustitución no presento efectos adversos sobre esta variable productiva. Con respecto a la talla, se observa una tendencia similar en ambas dietas sin presentar diferencias estadísticamente significativas durante las 6 semanas de evaluación $(P<0,05)$. Resultados similares, fueron reportados por Andrade-Yucailla et al., $(2015)$ y Lázaro et al., (2012), en la medida del hueso tarso-metatarso de gallinas (Gallus gallus domesticus), obteniendo valores entre 10,47 -14,14 cm para aves con pesos promedios de $1603-1920 \mathrm{gr}$, para ambos estudios.
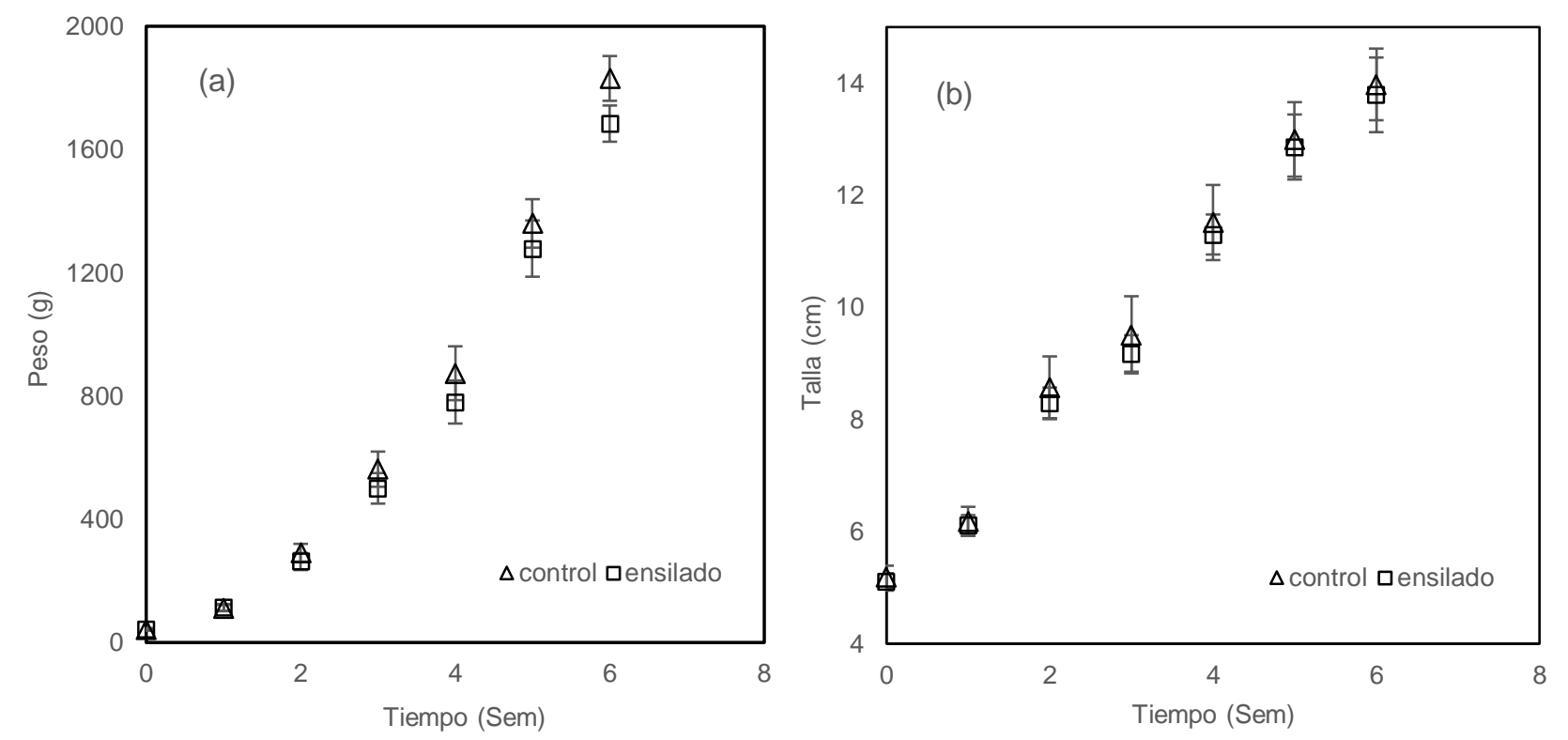

Fig. 1: Variables productivas de pollos de engorde. (a) peso semanal, (b)talla.

En la tabla 4 se observan las variables productivas consumo de alimento, porcentaje de mortalidad e índice de conversión de alimento de cada una de las dietas durante los 40 días de estudio, en ella los superíndices diferentes indican diferencias estadísticamente significativas. El análisis de varianza arrojó que las variables evaluadas no presentaron diferencias estadísticamente significativas $(P>0,05)$ entre ambas dietas. Con respecto al consumo de alimento, valores similares fueron reportados por Al-Marzoogi et al., (2010) quienes evaluaron el efecto de diferentes niveles de inclusión de ensilado de sardinas en dietas alimenticias para pollos de engorde, en donde el consumo de alimento se vio afectado positivamente a medida que se aumentó el porcentaje de inclusión, sin embargo, para en este estudio no se presentaron diferencias estadísticamente significativas $(p>0,05)$ entre ambas dietas.

El porcentaje de mortalidad no presentó diferencias estadísticamente significativas $(P>0.05)$ en función de la dieta, obteniendo el mismo número de aves muertas durante todo el periodo de estudio en ambos casos, con un límite máximo de 4.5\%. Este porcentaje es mayor al reportado por Shabani et al., (2019) quienes realizaron una inclusión de ensilado biológico de residuos de pescado en alimentación de pollos encontrando porcentajes de mortalidad en un rango de 2,08-2,96\%. Sin embargo, estos resultados fueron inferiores en comparación a los reportados por Venturoso et al. (2016) en alimentación de pollos de engorde con ensilado acido de residuos de pescado obteniendo porcentajes mortalidad entre $60-90 \%$, esto debido a la formación de aminas biogénicas que actuaron en la microbiota intestinal de las aves, modificando y promoviendo un marco de septicemia que evolucionó y condujo a la mortalidad de estas. Por último, el índice de conversión de alimento $(\mathrm{FCl})$ no presento diferencias estadísticamente significativas $(P>0.05)$ en función de la dieta y en 
función del tiempo de evaluación, adicionalmente este se encuentra dentro de los valores normales reportados para la línea de aves utilizada (Ross 308) (Rosero et al. 2012) indicando que la inclusión de ensilado quimíco de vísceras de tilapia roja en alimentación de pollos de engorde no presenta efectos adversos en la indice de consumo de alimento y su palatabilidad. Resultados similares para la última semana de estudio fueron reportados por Boitai et al., (2018) y Garcés et al. (2015) incorporando ensilado químico de vísceras de peces de agua dulce y vísceras de trucha arcoíris en dietas para pollos de engorde (Santana-Delgado et al., 2008).

Tabla 4. Variables productivas $(n=60)$

\begin{tabular}{|c|c|c|c|c|c|c|}
\cline { 2 - 7 } \multicolumn{1}{c|}{} & \multicolumn{3}{c|}{ Dieta control } & \multicolumn{3}{c|}{ Dieta ensilado } \\
\hline $\begin{array}{c}\text { Sem } \\
\text { ana }\end{array}$ & $\begin{array}{c}\text { Consumo de } \\
\text { alimento }(g r / a v e ~ d)\end{array}$ & $\begin{array}{c}\text { Mortalidad } \\
(\%)\end{array}$ & $\begin{array}{c}\text { Índice de } \\
\text { conversión de } \\
\text { alimento }\end{array}$ & $\begin{array}{c}\text { Consumo de } \\
\text { alimento }(g r / a v e ~ d)\end{array}$ & $\begin{array}{c}\text { Mortalidad } \\
(\%)\end{array}$ & $\begin{array}{c}\text { Índice de } \\
\text { conversión de } \\
\text { alimento }\end{array}$ \\
\hline $0-1$ & $14.60^{\mathrm{a}}$ & $0.00^{\mathrm{a}}$ & $1.42^{\mathrm{a}}$ & $15.80^{\mathrm{b}}$ & $0.00^{\mathrm{a}}$ & $1.36^{\mathrm{a}}$ \\
\hline $1-2$ & $43.10^{\mathrm{a}}$ & $0.00^{\mathrm{a}}$ & $1.56^{\mathrm{a}}$ & $42.80^{\mathrm{a}}$ & $0.00^{\mathrm{a}}$ & $1,65^{\mathrm{b}}$ \\
\hline $2-3$ & $69.70^{\mathrm{a}}$ & $2.70^{\mathrm{a}}$ & $1.67^{\mathrm{a}}$ & $70.00^{\mathrm{a}}$ & $2.70^{\mathrm{a}}$ & $1.74^{\mathrm{a}}$ \\
\hline $3-4$ & $111.50^{\mathrm{a}}$ & $0.00^{\mathrm{a}}$ & $1.80^{\mathrm{a}}$ & $111.70^{\mathrm{a}}$ & $2.70^{\mathrm{b}}$ & $1.87^{\mathrm{a}}$ \\
\hline $4-5$ & $135.00^{\mathrm{a}}$ & $0.00^{\mathrm{a}}$ & $1.73^{\mathrm{a}}$ & $134.60^{\mathrm{a}}$ & $0.00^{\mathrm{a}}$ & $1.69^{\mathrm{a}}$ \\
\hline $5-6$ & $179.00^{\mathrm{a}}$ & $2.70^{\mathrm{a}}$ & $1.78^{\mathrm{a}}$ & $179.00^{\mathrm{a}}$ & $0.00^{\mathrm{b}}$ & $1.78^{\mathrm{a}}$ \\
\hline Total & $3701.00^{\mathrm{a}}$ & $4.50^{\mathrm{a}}$ & $1.90^{\mathrm{a}}$ & $3698.00^{\mathrm{a}}$ & $4.50^{\mathrm{a}}$ & $1.89^{\mathrm{a}}$ \\
\hline
\end{tabular}

Los valores del hemograma y la química sanguínea de las aves se presentan en la tabla 5 con sus respectivos datos de referencia, letras diferentes en el superíndice indican diferencias estadísticamente significativas. Con respecto al porcentaje de hematocritos (HTO) se obtuvieron diferencias estadísticamente significativas $(\mathrm{P}<$ $0,05)$ entre ambas dietas, sin embargo, sus niveles se encuentran dentro del rango normal para la especie estudiada, entre 23-35\% (Gutiérrez et al., 2017), por lo que esta diferencia puede deberse a situaciones de estrés en el momento de toma de muestra como lo reporto (Franco-G et al. 2009). La concentración de hemoglobina $(\mathrm{HB})$ no presentó diferencias estadísticamente significativas $(P>0,05)$ entre las dietas, sumado a esto sus valores se encuentran dentro del rango típico, indicando que la inclusión del ensilado químico en la dieta no altera la concentración de hemoglobina en pollos de engorde, valores similares fueron reportados por Gutiérrez et al., (2017) quienes evaluaron la inclusión de probióticos en la alimentación de pollos de engorde. Con referencia a los glóbulos blancos (GB) se encontraron diferencias estadísticamente significativas $(P<0,05)$ entre ambas dietas, con valores en el rango normal para la especie, adicionalmente resultados similares fueron obtenidos por Avilez Colón et al. (2015) evaluando pollos de engorde criados en granjas del trópico bajo. Dentro de la serie blanca se evaluaron cuatro tipos de leucocitos básicos: heterófilos $(H)$, linfocitos $(L)$, eosinófilos $(E)$, monocitos $(M)$, los cuales se encontraron dentro de los parámetros establecidos para esta especie y solo los linfocitos mostraron diferencias estadísticamente significativas $(\mathrm{P}<$ 0,05 ) entre las dietas evaluadas, siendo estos los más predominantes para la especie utilizada (Schmidt et al. 2009). Esta diferencia puede deberse al sexo del ave puesto que según lo reportado por Avilez Colón et al. (2015) las aves machos presentan valores superiores en comparación con las aves hembras con respecto a este parámetro.

Tabla 5. Hemograma y química sanguínea $(n=6)$

\begin{tabular}{|l|l|l|l|c|c|l|l|l|l|l|l|}
\cline { 2 - 12 } \multicolumn{1}{c|}{} & $H T O(\%)$ & $H B(g / d L)$ & $\begin{array}{c}G B \\
(g / m m 3)\end{array}$ & $\begin{array}{c}H \\
(\%)\end{array}$ & $\begin{array}{c}L \\
(\%)\end{array}$ & $E(\%)$ & $M(\%)$ & $\begin{array}{c}P T \\
(g / d L)\end{array}$ & $\begin{array}{c}T G . \\
(m g / d L)\end{array}$ & $\begin{array}{c}C T \\
(m g / d L)\end{array}$ & $\begin{array}{c}A L T \\
(U I / L)\end{array}$ \\
\hline Ref. & $23-35$ & $8-19$ & $3000-11000$ & $30-75$ & $20-65$ & $0-5$ & $0-5$ & & & & \\
\hline Control & $27^{\mathrm{a}}$ & $8.9^{\mathrm{a}}$ & $4800^{\mathrm{a}}$ & $39^{\mathrm{a}}$ & $67.5^{\mathrm{a}}$ & $0^{\mathrm{a}}$ & $1^{\mathrm{a}}$ & $6.1^{\mathrm{a}}$ & $29.5^{\mathrm{a}}$ & $126^{\mathrm{a}}$ & $12.6^{\mathrm{a}}$ \\
\hline Ensilado & $25^{\mathrm{b}}$ & $8.3^{\mathrm{a}}$ & $5900^{\mathrm{b}}$ & $40^{\mathrm{a}}$ & $59^{\mathrm{b}}$ & $1.5^{\mathrm{a}}$ & $2^{\mathrm{a}}$ & $6.3^{\mathrm{a}}$ & $48^{\mathrm{b}}$ & $163,9^{\mathrm{b}}$ & $13.1^{\mathrm{a}}$ \\
\hline
\end{tabular}

Por otro parte, no se evidencian diferencias estadísticamente significativas $(P<0,05)$ en la proteína total $(P T)$ entre las dos dietas, indicando que esta no se vio influenciada por la inclusión de ensilado químico. Valores inferiores $(2,33-3,68 \mathrm{~g} / \mathrm{dL}$ ) fueron reportados por Lopez Miranda et al. (2007) y por Boitai et al., (2018) adicionando proteínas de origen vegetal como la harina de frijol durante la fase de crecimiento en pollos de engorde y ensilado de ensilado de residuos de pescado (vísceras y agallas) de agua dulce. Con respecto a los triglicéridos (TG) se presentaron diferencias estadísticamente significativas $(P<0,05)$ entre las dietas evaluadas, siendo mayor la concentración en la dieta ED, esto puede deberse a la concentración de lípidos principalmente de ácidos grasos presentes en el ensilado químico como fue reportado por Arias et al. (2017). Valores similares fueron encontrados por Azarfar (2013) y Cruz-Polycarpo et al. (2014) en alimentación de pollos de engorde con ensilado de maíz. El colesterol sérico (CT) presentó diferencias estadísticamente significativas $(p<0,05)$ entre ambas dietas, siendo la concentración en la dieta ED mayor que la dieta CD, esto es debido fundamentalmente a la concentración de lípidos en el ensilado químico de vísceras de tilapia 
roja (Tabla 2), ya que cuando la proporción de colesterol en la dieta es mayor, el hígado sintetiza menos cantidad de este, aumentando la concentración total de colesterol en sangre (Sumarsih et al. 2010). Sin embargo, valores similares a los obtenidos en la dieta ED fueron reportados por Darsana and Sreekumar (2012) suplementando dietas para pollos de engorde con ensilado biológico de residuos piscícolas. Por último, la enzima alanina aminotransferasa (ALT) es una enzima hepática que permite determinar patologías como inflamación o necrosis del hígado (Sanchez 2009). La concentración de esta no presentó diferencias estadísticamente significativas $(P<0,05)$ entre las dietas evaluadas, sumado a esto valores similares $(10-15$ $\mathrm{UI} / \mathrm{L}$ ) fueron reportados por Darsana and Sreekumar (2012) indicando que, en estas condiciones de trabajo y utilizando un $25.5 \%$ de ensilado químico en la dieta como sustituto de materias primas proteicas como harina de pescado y torta de soya, no afecta negativamente la función hepática del hígado y no presenta toxicidad en pollos de engorde.

\title{
CONCLUSIONES
}

De los resultados mostrados, de su análisis y de su discusión, se puede obtener las siguientes conclusiones, sobre el impacto del proceso de secado de alimento para tilapia roja y su influencia en características del producto: 1) El ensilado químico de vísceras de tilapia roja cuenta con las características bromatológicas y microbiológicas requeridas para ser usado como fuente de proteína en la alimentación de aves de corral como pollos de engorde. 2) Los parámetros productivos, hematológicos y de química sanguínea de las aves, no se ven afectados por la inclusión del ensilado en las dietas, encontrándose dentro del rango normal para la línea de pollos de engorde utilizada (Ross 308). Sin embargo, el colesterol y los triglicéridos de la dieta ED, pueden verse incrementados debido a la concentración de lípidos y ácidos grasos presentes en el ensilado. 3) El diseño de dietas utilizando ensilados de tilapia como fuente de proteínas es técnicamente viable puesto que aporta los nutrientes necesarios para el crecimiento de pollos de engorde sin afectar de manera negativa la salud de los mimos.

\section{AGRADECIMIENTOS}

Los autores del presente trabajo agradecen al comité para el desarrollo de la investigación en la Universidad de Antioquia (CODI) y al Ministerio de Ciencia Tecnología e innovación (MINCIENCIAS) por el apoyo financiero a través del proyecto 1115-745-58746.

\section{NOTACION}

\author{
Abreviaciones \\ $\mathrm{AOAC}=$ Association of Official Analytical Chemists \\ $\mathrm{BHT}=$ Butil hidroxi tolueno \\ $\mathrm{EQ}=$ Ensilado químico \\ $\mathrm{CD}=$ Dieta control \\ $\mathrm{ED}=$ Dieta ensilado \\ $\mathrm{NTC}=$ Norma técnica colombiana \\ $\mathrm{FCl}=$ Índice de conversión de alimento \\ $\mathrm{M}=$ Mortalidad \\ $\mathrm{HTO}=$ Hematocrito \\ $\mathrm{HB}=$ Hemoglobina \\ $\mathrm{GB}=$ Glóbulos blancos \\ $\mathrm{H}=$ Heterófilos \\ $\mathrm{L}=$ Linfocitos \\ $E=$ Eosinófilos \\ $\mathrm{M}=$ Monocitos \\ $\mathrm{PT}=$ Proteína total \\ $\mathrm{TG}=$ Triglicéridos \\ $\mathrm{CT}=$ Colesterol sérico \\ $\mathrm{ALT}=$ Enzima alanina aminotransferasa
}

\section{REFERENCIAS}

Al-Marzooqi, W., Al-Farsi, M., y otros tres autores, The effect of feeding different devels of sardine fish silage on broiler performance, meat quality and sensory characteristics under closed and open-sided housing systems, https://do.org/10.5713/ajas.2010.10119, Asian-Aust. J. Anim. Sci., 23(12) 1614-25 (2010) 
Andrade, V., Vargas, J., y otros cuatro autores, Caracterización morfométrica y morfológia de la gallina criolla (Gallus Domesticus) del cantón Carlos Julio Arosemena, Ecuador, Actas Iberoamericanas de Conservación Animal. 6 (June 2016) 42-48 (2015)

Arias, L., Gómez, L., y Zapata, J., Efecto de temperatura-tiempo sobre los lípidos extraídos de vísceras de tilapia roja (Oreochromis sp.) utilizando un proceso de calentamiento-congelación, https://do.org/i10.4067/s071807642017000500014, Inf. Tecnol., 28(5), 131-142 (2017)

Avilez, B., Rugeles C., y otros dos autores, Parámetros hematológicos en pollos de engorde criados en una granja de producción cerrada en el trópico bajo, https://do.org/10.19052/mv.3444, Rev. Med. Vet., 4(29) 33 (2015)

Azarfar, A., Effect of hemicell enzyme on the performance, growth parameter, some blood factors and ileal digestibility of broiler chickens fed corn/soybean-based diets, https://do.org/10.5897/jcab2013.0373, J. Cell Anim. Biol., 7(7) 85-91 (2013)

Barbosa, E., Rabello, C., y otros tres autores, Amino acid composition, and determination and prediction of the protein digestibility of different sugarcane yeasts in broilers, https://do.org/10.5935/1806-6690.20180038, Rev. Cienc. Agron. 44 334-342 (2018)

Boitai, S., Lakshman, K., y otros cinco autores, Effect of dietary incorporation of fish silage on growth performance, serum biochemical parameters and carcass characteristics of broiler chicken, https://do.org/10.18805/ijar.B-3315, Indian J. Anim. Res., 52(7) 1005-9 (2018)

Botello, A., Conservación in Vitro de tres ensilajes de pescado (Opisthonema Oglinum) caracterización físico-química, https://do.org/10.18805/ijar.B-3315, Rev. Electron. Granma Cienc., 14(1027-975X) 1-15 (2010)

Clark, P., Boardman, W., y Raidal, S., Atlas of clinical avian hematology, edited by W., and S., Phillip Clark and Blackwell (2012)

Cruz-Polycarpo, V., Sartori, J., y otros siete autores, Feeding high-moisture corn grain silage to broilers fed alternative diets and maintained at different environmental temperatures, https://do.org/10.1590/1516-635x1604449-458, Rev. Bras. Cienc. Avic., 16(4) 449-58 (2014)

Darsana, M., y Sreekumar, K., Effect of processed fish wastes supplementation on blood biochemical and meat composition of broiler chicken, Iran. J. Vet. Res., 13(3) (2012)

Fernández, A., Tabera, A., y otros dos autores, Obtención, caracterización microbiológica y físicoquímica de ensilado biológico de anchoita (Engraulis Anchoita), Rev. Electron. Vet., 14 1695-7504 (2013)

Franco, M., Hoyos, L., y otros dos autores, Hallazgos hematológicos y química sanguínea en amazona amazonica y amazona ochrocephala cautivas de la reserva forestal torre cuatro, Boletín Científico, Centro de Museos, Museo de Historia Natural, 13(2) 63-77 (2009)

Garcés, Y., Perea, C., y otros tres autores, Efecto nutricional del ensilado químico de subproductos piscícolas en la alimentación de pollos de engorde (Gallus domesticuset), Cuba. J. Agric. Sci, 49(4) 503-8 (2015)

Gaviria G, Y.S., Londoño L., y Zapata, J., Effects of chemical silage of red tilapia viscera (Oreochromis spp.) as a source of protein on the productive and hematological parameters in isa-brown laying hens (Gallus gallus domesticus), https://do.org/10.1016/j.heliyon.2020.e05831, J. Heliyon 6(12) 2020

Güllü, K., Acar, U., y otros dos autores, Replacement of fish meal with fish processing by-product silage in diets for the rainbow trout, Oncorhynchus mykiss, Pakistan J. Zool. 46 1697-1703 (2014)

Gutiérrez, L., y Corredor, J., Parámetros sanguíneos y respuesta inmune en pollos de engorde alimentados con probióticos, https://do.org/10.17151, Vet. Anim. Sci., 11(2) 81-92 (2017)

Lázaro, G., Hernández, J., y otros tres autores, Uso de Caracteres morfometricos en la clasificación de gallinas locales, Actas Iberoamericanas de Conservación Animal, November109-14 (2012)

Leinonen, I., Williams, A., y otros tres autores, Predicting the environmental impacts of chicken systems in the United Kingdom through a life cycle assessment: Broiler production systems, http://dx.doi.org/10.3382/ps.2011-01634, Poult. Sci. J. 91 8-25 (2012)

Lopez, S., Reyes, H., y otros tres autores., Productive parameters and blood chemistry in broiler chickens Fed with three dietary levels of cowpea grain meal (Vigna Unguiculata) during growth phase. Rev. Cien. XVII, 0798-2259 150-60 (2007)

Nunes, G. F., La sostenibilidad de la industria avícola, La Habana, Cuba (2009)

Rosero, J. Ferney, E., y Lopez, F., Evaluación del Comportamiento Productivo de las lineas de pollos de engorde cobb 500 y ross 308, Biotecnología en el Sector Agropecuario y Agroindustrial, 10(1) 8-15 (2012)

Sanchez, G., Función hepática y parámetros analíticos, Laboratorio de Analisis Veterinario Arturo Soria 6 (2009)

Santana-Delgado, H., Avila, E., y Soleto, A., Preparation of silage from Spanish mackerel (Scomberomorus maculatus) and its evaluation in broiler diets, https://do.org/10.1016/j.anifeedsci.2007.05.023, Anim. Feed Sci. and Tech., 141129140 (2008)

Schmidt, E., Paulillo, A., y otros seis autores, Hematology of the bronze turkey (Meleagris Gallopavo): variations with age and gender, https://do.org/10.3923/ijps.2009.752.754, Int. J. Poult. Sci., 8(8) 752-54 (2009) 
Shabani, A., Jazi, V., y otros dos autores, Inclusion of fish waste silage in broiler diets affects gut microflora, cecal shortchain fatty acids, digestive enzyme activity, nutrient digestibility, and excreta gas emission, http://dx.doi.org/10.3382/ps/pez244, Poult. Sci. J., 98(10) 4909-18 (2019)

Spanopoulos-Hernandez, M., Ponce-Palafox, J., y otros cinco autores, Production of biological silage from fish waste, the smoked yellowfin tuna (Thunnus Albacares) and fillet of tilapia (Oreochromis Sp), for feeding aquaculture species, Rev. Mex. Ing. Quím., 9(2) 167-78 (2010)

Suarez, L., Montes, J., y Zapata, J., Optimización del contenido de ácidos en ensilados de vísceras de tilapia roja (Oreochromis spp.) con análisis del ciclo de vida de los alimentos derivados, https://do.org/10.4067/s071807642018000600083, Inf. Tecnol., 29(6), 83-94 (2018)

Sumarsih, S., Yudiarti, T., y otros tres autores, The influence of using fish fermented by lactic acid bacteria as feed substitution on serum lipid profile of broilers, http://dx.doi.org/10.14710/jitaa.35.2.124-128, J. Indones. Trop. Anim. Agric., 35(2) 124-28 (2010)

Venturoso, O., Reinicke, F., y otros seis autores, Silagem acida de resíduos de peixes para frangos de corte, http://dx.doi.org/10.21708/avb.2016.10.3.5412, Acta Vet. Bras., 10(3) 284-89 (2016) 
